\title{
AC 2010-1694: BUILDING INFORMATION MODELING IN CONSTRUCTION: CURRENT PRACTICES AND THEIR IMPLICATIONS FOR CONSTRUCTION ENGINEERING EDUCATION
}

Anthony Mutai, Bowling Green State University

Stan Guidera, Bowling Green State University 


\title{
Building information modeling in construction: Current practices and their implications for construction engineering education
}

\begin{abstract}
This paper reports the findings of research intended to document the current status of adoption and use of Building information Modeling (BIM) in the construction industry. BIM utilizes 3D computer models, developed using software applications based on Object Oriented Programming that integrate 3D-2D operations. This study utilized an online survey which was sent to 236 construction firms drawn from the top 400 contractors listed in the 2008 Engineering News Record (ENR) who were identified as having over $80 \%$ of their projects categorized as general building ${ }^{2}$. The study utilized the following expanded utilization-level categorization: level 1 (use of BIM technology that is limited to 2D and 3D capabilities for document production and visualization functions), level 2 (use of BIM for additional analysis done on the 2D and 3D data that is based on geometry and positioning of building systems including change management of 2D and 3D documents, and conflict/clash detection between different building systems), and level 3 (includes in addition to levels $1 \& 2$, the use of BIM for all other functions including cost and scheduling). The response rate was $48 \%$ of the total firms included in the survey, most with multiple respondents. This paper documents the data collected and the data analysis and procedures used to categorize the responses relative to the level of BIM use. The data is then used to provide a framework for recommendations to construction engineering faculty interested in integrating BIM technologies into their courses and curriculums and aligning instructional outcomes with the current and anticipated utilization of Building Information Modeling in the construction industry.
\end{abstract}

\section{Introduction}

Building Information Modeling (BIM) has been defined as a "project simulation consisting of the 3D models of the project components with links to all the required information connected with the projects' planning, construction or operation, and decommissioning" ${ }^{1}$. It is a digital representation of physical and functional characteristics of a facility providing accurate 3D representation of a building and the capability to affiliate attributes and data to the components and objects that form the model ${ }^{2}$. Similarly, the National Institute of Building Sciences published the following definition:

"Building information models, or BIMs (are) digital, easily managed and shared representations of physical and functional data that define buildings throughout their life cycles-are increasingly seen throughout the public and private real estate and construction sectors as a way to control cost and performance problems associated with inaccurate and incomplete communications" ${ }^{3}$.

Central to these definitions is the concept that the BIM is as a database made up of interrelated files organized within or linked to the 3D digital model. The concept of BIM is to construct a building virtually, prior to constructing it physically, in order to resolve and simulate any potential design conflicts ${ }^{2}$. Architecture, engineering, and construction professionals have been adopting BIM technology to improve business processes in AEC project delivery ${ }^{4}$. 
In relation to the potential productivity benefits, a key driver of the adoption of BIM are initiatives in AEC industry. The Association of General Contractors (AGC) has launched the AGC BIM initiative, supported by a publication for members entitled "Contractors guide to BIM" 5 . The American Institute of Architects Technology in Architectural Practice (TAP) division has developed an awards program to recognize projects that exhibit exemplary use of integrated and interoperable building information modeling ${ }^{6}$. Additionally, the National Institute of Building Sciences, an organization authorized in 1974 to serve as an interface between government and the private sector to improve the building regulatory environment and facilitate the introduction of new and existing products and technology into the building process ${ }^{7}$, has also introduced a BIM initiative. It has established a committee referred to as NBIMS (the National Building Information Model Standard) as means of developing national standards for $\mathrm{BIM}^{3}$.

However, these developments are being driven in part by an initiative being sponsored by U.S. General Services Administration. The General Services Administration, which is the largest single procurer of design services in the United States, launched the GSA BIM initiative in 2003 with three specified intended outcomes; to maintain and advance design excellence, to bring in projects on-time and within budget, and to enable project life-cycle knowledge transfer. As of late 2006, the GSA's Office of the Chief Architect had completed 10 pilot projects and had 25 additional projects under way ${ }^{8}$. The GSA BIM initiative requires that all projects commissioned by the GSA utilize fully integrated Building Information Modeling for project delivery from design through construction beginning in Fiscal Year 2007 . According to the GSA "the purpose of BIM is to make the design information explicit so that the design intent and program can be immediately understood and evaluated. They further stated that "a BIM-based approach supports 'on demand' generation of documents (e.g., drawings, lists, tables, and 3D renderings) from a consistent Building Information Model" 10, 11.

\section{General Overview of BIM Technology}

The traditional way of exchanging information in the AEC industry is document centered ${ }^{12}$. Documents include 2D drawings, written specifications, manually calculated bill of material quantities, etc. Although computers have automated the process of document production, the data exchange and management procedures are still focused on paper-based documents because of the legal implications for digital exchange of project data that are still new within the AEC industry ${ }^{12}$. Other researchers and industry experts have argued that most design communication is still done using 2D drawings and other text documents ${ }^{13}$. This finding is also confirmed by another study by Kiviniemi, Tarandi, Karlshøj, Bell, and Karud, where the slow pace of BIM adaptation was explained using the issues of overcoming the $2 \mathrm{D}$ versus $3 \mathrm{D}$ working cultures that are still relatively new within the industry ${ }^{14}$.

However, BIM as both a technology and a process provides an array of technological advantages over conventional CAD documentation and project management and delivery. As opposed to previous 3D CAD systems that used polygonal surface modeling, BIM applications utilize parametric modeling. Parametric modeling involves the use of relational databases containing information regarding the elements of a structure and their relationships. The capture and 
management of object relationships is useful in enabling a high level of model analysis beyond object properties.

BIM applications are based on object-oriented technology, a technology based on the use of digital representations of the physical elements of the building such as walls, doors, floors, etc.

15. Objects also include definitions of abstract concepts including: relationships (such as connections and adjacency), object-oriented definitions (such as wall type and door type), hierarchies (such as containment), and groupings (such as zones and systems).

Properties are attached to objects in order to identify and describe them in some way. The properties vary in terms of their type and detail. Typically these properties are defined in a BIM authoring application and can then be used by analysis and simulation applications to assess design performance such as thermal, structural, and cost attributes ${ }^{16}$.

\section{Level of BIM use}

Some scholars have attempted to classify the use of BIM. Jernigan ${ }^{17}$ classified BIM use into two groups, small BIM and big BIM ${ }^{17}$. He described small BIM as a term representing applicationcentric topics such as an individual's use of BIM application such as Revit, Archicad, Bentley, etc. He explained that small BIM can be regarded as software on personal computers that does not consider connectivity between project team members.

Fox and Hietanen developed a framework for describing the scope of BIM use across a broad range of AEC companies during building design, construction, and operation ${ }^{18}$. As shown in Figure 6, they identified four types of BIM use based on the number of domains and the number of organizations participating is the BIM process.

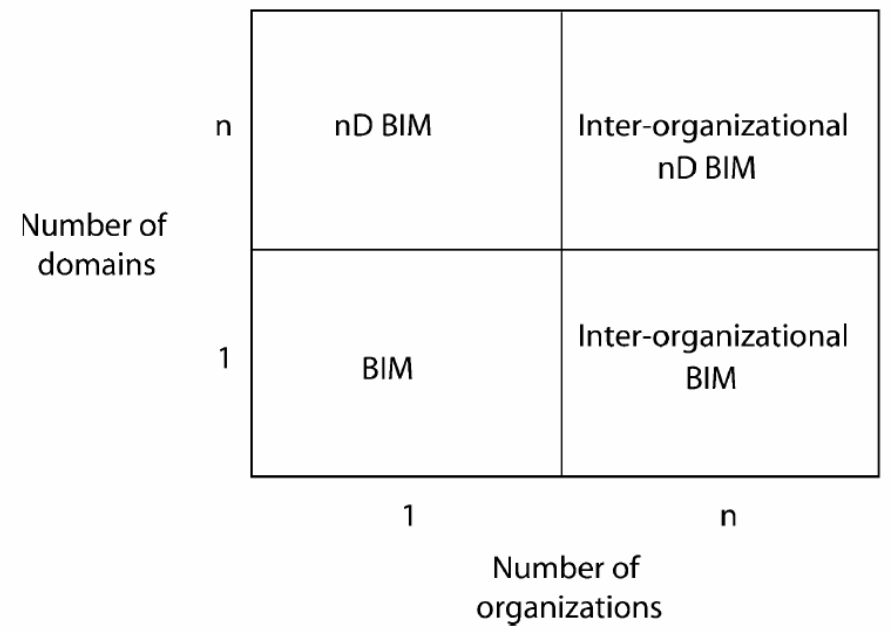

Figure 1. Scope of BIM Use (Fox and Hietanen, 2006).

They noted that BIM technology can be used within one organization only. Alternatively, BIM generated data can be shared by a number of organizations. Further, BIM usage may encompass only one domain or functional dimension. Alternatively, the use of BIM may encompass a number of domains $(\mathrm{nD})$. This ordering of BIM uses in a relational manner was useful in clarifying the BIM capabilities of different organizations participating in the study ${ }^{18}$. 
Beyond its inherent use of 3D modeling, BIM can be also used for what is referred to as 4D and 5D data. While a 2007 study of BIM utilization found that majority of BIM users are using the technology for drawing generation, visualization, and clash detection the data also indicated that approximately $48 \%$ of the respondents indicated that they are finding business value in the use of 4D technology as shown in Figure $2^{4}$.

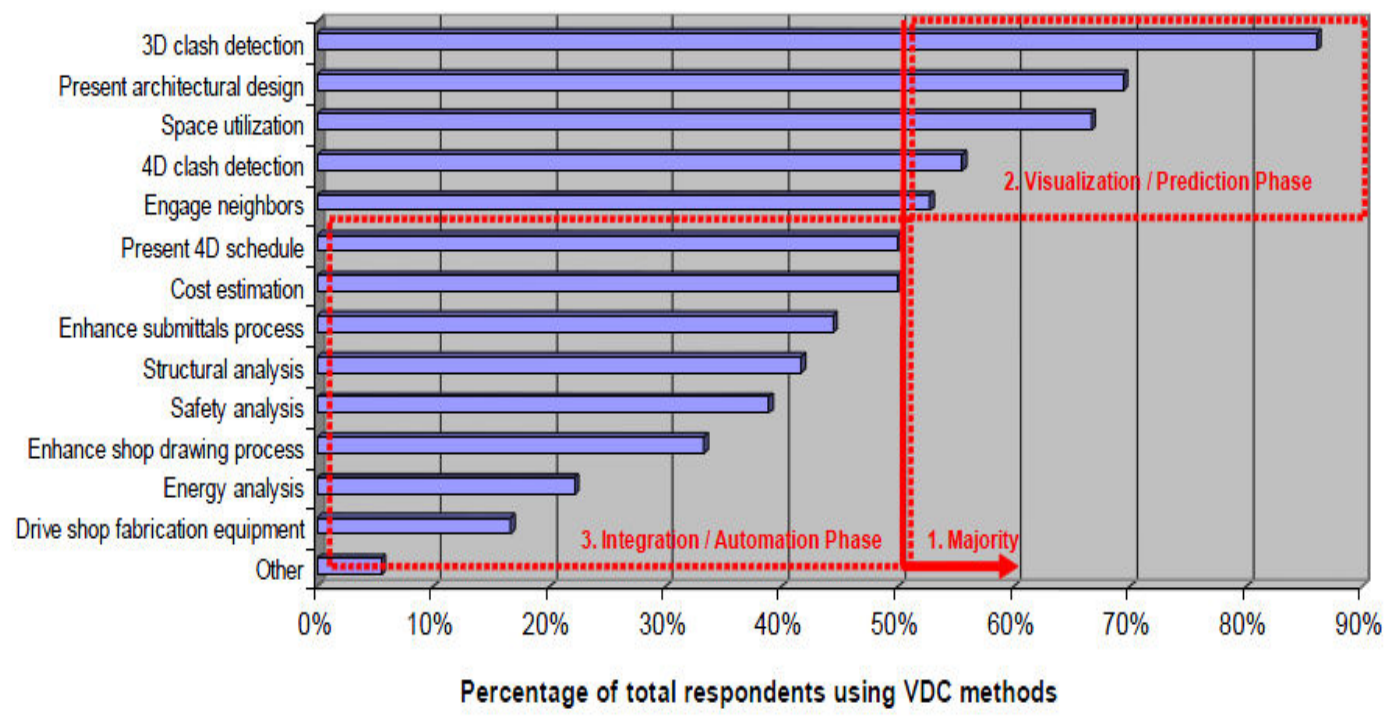

Figure 2. Business Value of Using BIM at Individual Organizations (Giligan and Kunz, 2007).

4D modeling technology involves the use of 3D models as the basis for planning and managing construction projects. The 3D models are linked to the project schedule thereby providing project stakeholders with an opportunity to analyze what-if scenarios ${ }^{19}$. This allows materials or processes to be tested virtually under controlled conditions before committing resources and without risk for expensive failure ${ }^{12}$. Currently the Critical Path Method (CPM) is widely used for project planning. Jongeling et al. explained that the construction schedule typically represented as a Gantt chart, mainly concentrates on the temporal aspect of construction planning (i.e., the time aspect) ${ }^{20}$. They noted that construction projects have unique spatial configurations and this spatial quality is important in project planning. For this reason, CPM schedules do not provide spatial information and therefore users need to review $2 \mathrm{D}$ drawings to conceptually associate components with the related activities thereby limiting the evaluation of alternative scheduling solutions ${ }^{20,21}$. 4D modeling is identified as a tool for visually conveying planning information, as an integration tool that enhances collaboration among project participants, and as an analysis tool that supports users to conduct additional analysis ${ }^{22,23}$.

5D technologies involve the integration of BIM models with cost data in order to facilitate the cost estimating process ${ }^{12}$. Object-oriented 3D CAD systems can often calculate and make project reports for quantity of materials needed also known as a Bill of Materials (BOM). This is possible because the CAD objects are parametric and are built up by different property values that generate the graphics like height, width, length, etc. This allows the calculation of volumes and surface areas of building elements contained in a BIM model. These objects can also be added with non-graphical properties like material, classification code, unit cost, etc ${ }^{15}$. 
The extent to which BIM is utilized in the AEC industries and professions has significant implications for educators in the disciplines in and related to construction. These initiatives and mandates suggest that competency with BIM applications will become increasingly important for engineers and construction management professionals. Consequently, educators in all fields related to the AEC industry must consider the role of BIM technology in both design and technical education. More importantly, it can be assumed that there will be an expectation among AEC professionals that construction curriculums will be integrating BIM skill development so that graduates will have developed competencies with BIM technology. However, in order to establish strategies for BIM skill development, documentation of the ways construction professionals are utilizing BIM could provide critical guidance for AEC educators.

\section{Purpose of the study}

Specific skills can be associated with the level of BIM use. For example, small BIM skill sets would emphasize skill in generating accurate 3D that fully document a building or structure. Expertise with generating and storing information with a specific application such as Revit or ArchiCad would have priority. In contrast, big BIM would require more diverse sets that include not only a broader range of applications such as cost estimating and error detection but also skills in sharing and acquiring data from multiple sources. However, given the complexity of BIM utilization, it was determined that a more specific classification of BIM use may provide greater insight.

This study was developed to identify the factors that influence the use of BIM technology within construction firms. This included documenting types of projects as well as level of use. In this study, a framework was developed for classifying the level of BIM use based on the rationale used by Fox and Hietanen ${ }^{18}$. Categories of BIM use were developed based on how BIM generated data is shared between project team members.

Table 1. Level of BIM Use.

\begin{tabular}{|c|c|c|c|c|}
\hline & \multicolumn{4}{|c|}{ Category of use (extent of data sharing) } \\
\hline \multirow{4}{*}{ 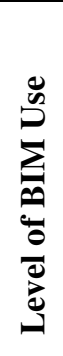 } & & $\begin{array}{l}\text { Small } \\
\text { (Intra-Departmental) }\end{array}$ & $\begin{array}{l}\text { Medium } \\
\text { (Intra-Organizational) }\end{array}$ & $\begin{array}{l}\text { Big } \\
\text { (Inter-Organizational) }\end{array}$ \\
\hline & Level 1 & & & \\
\hline & Level 2 & & & \\
\hline & Level 3 & & & \\
\hline
\end{tabular}

As seen in Table 1, three categories of BIM use were identified: small BIM, medium BIM, and big BIM. Small BIM refers to localized use of BIM in which the data generated is used only within one department. in an organization. Medium BIM refers to use of BIM in which data generated is used between different departments within an organization but with no interorganizational connectivity. Big BIM refers to coordinated inter-departmental and interorganizational use of BIM generated data. Big BIM involves multidisciplinary teams collaborating and sharing BIM generated data using a variety of options such as use of ftp sites, project portals, and project planning applications such as the Onuma Planning System (OPS). 
Each of these categories is further classified into the following three levels of use based on the functional applications of BIM use, level 1, level 2, and level 3. Level 1involves use of BIM technology that is limited to $2 \mathrm{D}$ and 3D capabilities for document production and visualization functions. At this level, there is no analysis done on the models beyond visualization. Level 2 involves additional analysis done on the 2D and 3D data including change management of 2D and 3D documents, and conflict/clash detection between different building systems. In other words this analysis is limited to geometry-centric analysis such as positioning and dimensions of building elements. It does not involve any analysis related to building performance. Level 3 includes use of BIM for all other functions including and beyond those described in levels 1 and 2. It involves the use of a variety of functional domains such as $2 \mathrm{D}, 3 \mathrm{D}, 4 \mathrm{D}, 5 \mathrm{D}$, and $\mathrm{nD}$. This framework was used to categorize the levels of BIM use of participating organizations.

\section{Study Population}

This study specifically focused on the top 400 contractors listed in the September 22, 2008 Engineering News Record (ENR) which includes companies with a variety of different market focuses, including general building, manufacturing, power, waste, industrial, transport, and telecommunication ${ }^{24}$. Ranking on this list is based on the total contractor's total revenue in the year 2007. However the sample targeted for this study focused on those firms with a general building market focus exceeding $80 \%$, which yielded a total of 236 companies for the study population.

\section{Research Questions}

The focus of the study was structured around the following research questions:

1. To what extent is BIM technology being utilized within the leading construction firms in the United States of America?

2. What are the project types that the leading construction companies in the US are using BIM for?

3. What is the respondents' perception of their organizations perceived expertise with the use of BIM?

4. What are the specific BIM features and functions that the leading construction companies in the US are using?

5. What is the BIM level that the leading construction firms in the United States of America are using?

\section{Survey Organization and questions}

The survey first asked questions used to collect demographic data regarding firm size, with respondents choosing between "Less than 20", "20-99", "100-50", or "More than 500", and client services offered using the categories General Contracting, Design Build Services, Construction Management Services, Design Services, and Other. The format of these questions is documented in Appendix A.

In order to collect data related to the research questions, the survey asked respondents what percentage of projects within their organization utilized BIM technologies and what project types 
do typically utilized BIM technology. The survey then asked respondents to rate their organizations level of BIM expertise using a five-point likert-type scale, ranging from "none" to "expert". The format of these questions is documented in Appendix A. Lastly, to determine the level and category of use, the survey asked respondents to indicate which BIM functions their organization utilized and how BIM-generated data was used within their organization including how this data is shared with other project stakeholders.

\section{Questionnaire Delivery}

The questionnaire was delivered in an electronic format through the Internet. The on-line version was designed to allow participants to take a break and re-enter the survey at the point where they left off and to make changes to their entries before finalizing their submission. This format provided the ability to monitor how many respondents had completed the survey by the cut-off date and take the necessary action to encourage non-respondents to complete it (follow-up emails and telephone reminders were extensively used). Prior interviews conducted as part of the instrument validation process were used to provide deeper understanding of the variables under investigation.

\section{Data and findings}

\section{Descriptions of Demographic data}

Questions in section 1 (participant information) were analyzed using descriptive techniques in which frequencies, percent, valid percent, and cumulative percent tables were generated. The following section provides detailed descriptions of the participants' information.

\section{Description of Firm Sizes}

As shown in Table 8, the majority of the surveyed firms had over 100 employees. Approximately $28 \%$ had between 100 and 500 employees while approximately $61 \%$ had over 500 employees. This can probably be explained by the fact that the study focused on the top 400 companies by revenue according to the September 22, 2008 ENR magazine. As it would be expected, these are relatively large companies employing over 100 persons.

Table 2. Company Sizes Based on Number of Employees.

\begin{tabular}{llcccc}
\hline \hline & & Frequency & Percent & Valid Percent & Cumulative Percent \\
\hline Valid & Less than 20 & 2 & 1.8 & 1.9 & 1.9 \\
& $20-99$ & 5 & 4.4 & 4.6 & 6.5 \\
& $100-500$ & 32 & $\mathbf{2 8 . 3}$ & 29.6 & 36.1 \\
& More than 500 & 69 & $\mathbf{6 1 . 1}$ & 63.9 & 100.0 \\
& Total & 108 & 95.6 & 100.0 & \\
Missing & System & 5 & 4.4 & & \\
Total & & 113 & 100.0 & & \\
\hline \hline
\end{tabular}




\section{Services Provided by Organizations Surveyed}

The organizations surveyed varied in the type of service provided to their clients. The majority of the firms provided general contracting, construction management, and design build services. It was noted that a few firms provided both contracting and design services as shown in Table 3.

Table 3. Services Offered by Surveyed Firms.

\begin{tabular}{llcccc}
\hline \hline & & & & Valid & Cumulative \\
Valid & General Contracting (GC) & 2 & 1.8 & 1.8 & 1.8 \\
& Construction Management (CM) & 3 & 2.7 & 2.7 & 4.5 \\
& Design Build (DB) & 5 & 4.4 & 4.5 & 9.0 \\
& GC \& CM & 1 & .9 & .9 & 9.9 \\
& GC, CM, \& DB & 32 & 28.3 & 28.8 & 38.7 \\
& CM, \& DB & 27 & 23.9 & 24.3 & 63.1 \\
& GC \& DB & 13 & 11.5 & 11.7 & 74.8 \\
& CM,DB, Design Services (DS) & 7 & 6.2 & 6.3 & 81.1 \\
& GC,CM,DB, DS & 18 & 15.9 & 16.2 & 97.3 \\
& Other & 3 & 2.7 & 2.7 & 100.0 \\
& Total & 111 & 98.2 & 100.0 & \\
Missing & System & 2 & 1.8 & & \\
Total & & 113 & 100.0 & & \\
\hline \hline
\end{tabular}

\section{Section 2: Description of Respondents' Use of BIM Technology}

Questions in section 2 (general use of BIM technology) were also analyzed using descriptive statistical techniques in which frequencies, percent, valid percent, and cumulative percent tables were generated. The following section provides detailed descriptions of the general BIM use.

\section{Description of BIM Use}

As shown in Table 4, (96.5\%) of the companies surveyed indicated that they utilized BIM technology in their projects. This indicates that most of the leading construction firms surveyed in this research project utilize BIM technology.

Table 4. Use of BIM Technology.

\begin{tabular}{llcccc}
\hline \hline & Frequency & Percent & Valid Percent & Cumulative Percent \\
\hline Valid No & 4 & 3.5 & 3.5 & 3.5 \\
& Yes & 109 & $\mathbf{9 6 . 5}$ & 96.5 & 100.0 \\
& Total & 113 & 100.0 & 100.0 & \\
\hline \hline
\end{tabular}




\section{Description of Proportion of Projects on Which BIM is Utilized}

As indicated in Figure 16, 87\% of the companies surveyed indicated that they utilize BIM technology on less than $40 \%$ of their projects. Approximately $40 \%$ indicated that they used BIM on between $21-40 \%$ of their projects. Only $4 \%$ indicated that they use BIM on more than $80 \%$ of their projects. Therefore, the data indicate that most leading construction firms utilize BIM technology, but the proportion of BIM use varies.

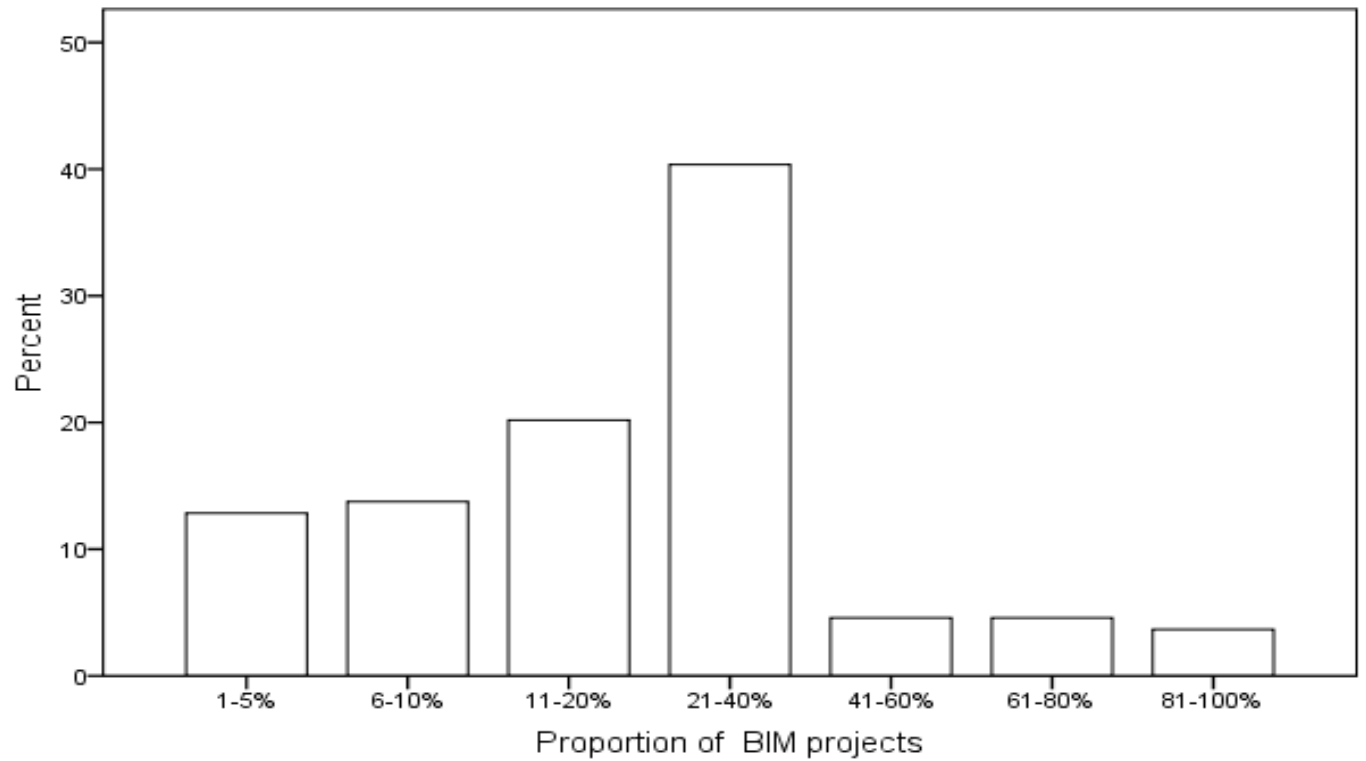

Figure 3. Proportion of BIM Use by Number of Projects.

\section{Description of Project Types on Which BIM Technology is Utilized}

The surveyed companies indicated that they use BIM technology on a variety of project types. As shown in Figure 4, these included: institutional, commercial buildings, medical facilities, 
educational, sports facilities, residential, and industrial projects.



Figure 4. Type of Projects in Which BIM Technology is Used.

\section{Description of Company Level of Experience on the Use of BIM Technology}

The surveyed companies varied in terms of their levels of experience in the use of BIM technology ranging from none users, beginners, intermediate, advanced, and expert. This scale was adopted from previous studies on the use of BIM technology. As shown in Table 5, respondent's perception on their company's level of experience in using BIM varied from none (3.5\%), beginners (8\%), intermediate (44.2\%), advanced (23.9\%), and expert (20.4\%).

Table 5. Company Experience on BIM Use.

\begin{tabular}{llcccc}
\hline \hline & & & & Cumulative \\
Valid & None & 4 & 3.5 & 3.5 & 3.5 \\
& Beginner & 9 & 8.0 & 8.0 & 11.5 \\
& Intermediate & 50 & 44.2 & 44.2 & 55.8 \\
& Advanced & 27 & 23.9 & 23.9 & 79.6 \\
& Expert & 23 & 20.4 & 20.4 & 100.0 \\
& Total & 113 & 100.0 & 100.0 & \\
\hline \hline
\end{tabular}




\section{Description of BIM Functional Applications}

The surveyed companies indicated that they utilize BIM technology on a variety of functions. As shown in Figure 5, these included: marketing, drawing production, 3D visualization, quantity take off, cost estimating, scheduling/project planning, clash detection, on-site project management, and analysis of building performance.

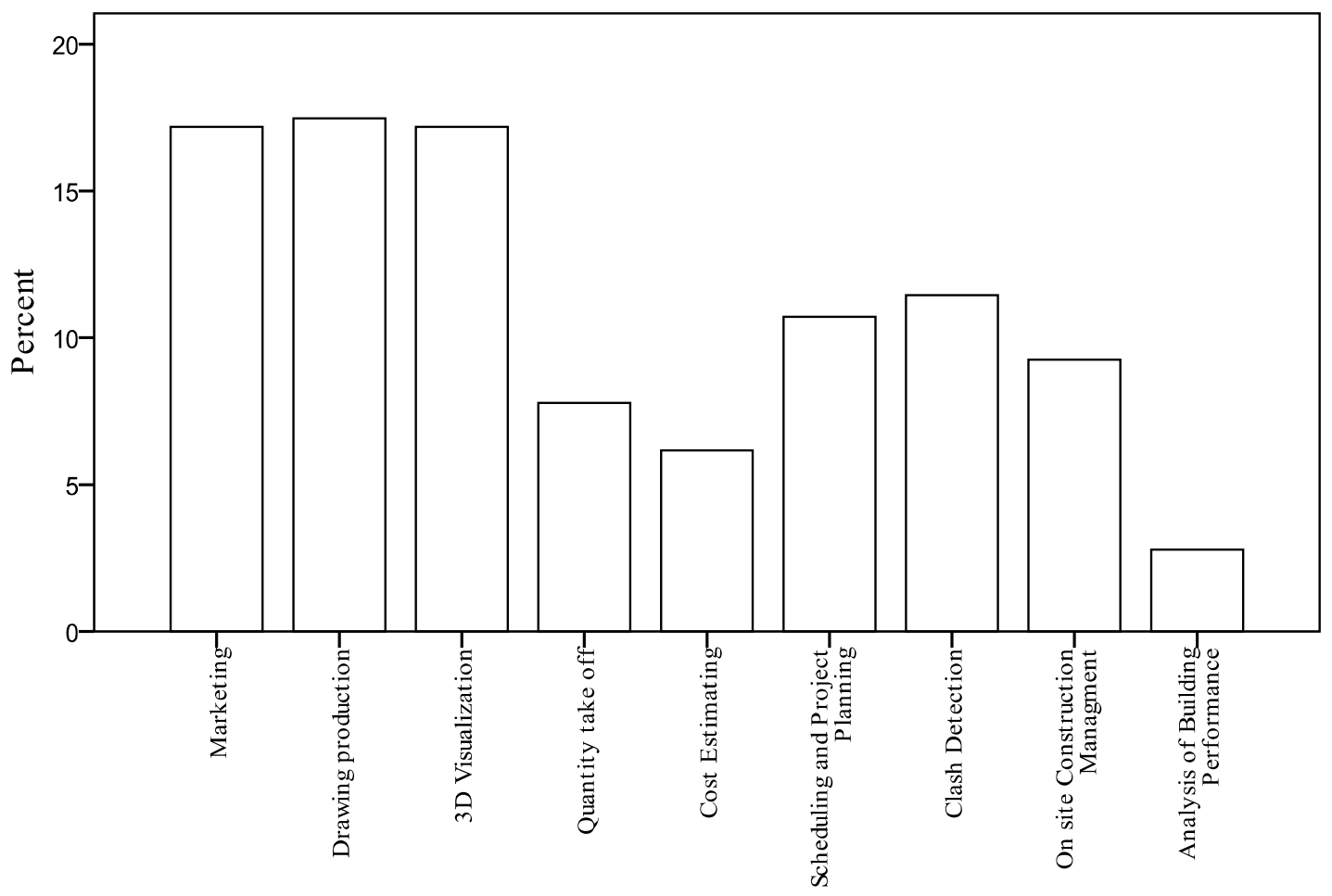

BIM Functions

Figure 1. Functional Applications of BIM Technology.

Based on these results, and as shown in Table 6,52.2\% of the companies fell under level 3 of BIM functional use, $31.0 \%$ fell under level 2, while $13.3 \%$ fell under level 1. Based on the criteria for grouping BIM use based on functional applications, that data indicated that most companies frequently use BIM technology for level 1 related functions (limited to 2D and 3D capabilities for document production and visualization functions).

Table 6. BIM Level of Use.

\begin{tabular}{llcccc}
\hline \hline & & Frequency & Percent & Valid Percent & Cumulative Percent \\
\hline Valid & 0 & 4 & 3.5 & 3.5 & 3.5 \\
& Level 1 & 15 & $\mathbf{1 3 . 3}$ & 13.3 & 16.8 \\
& Level 2 & 35 & $\mathbf{3 1 . 0}$ & 31.0 & 47.8 \\
Level 3 & 59 & $\mathbf{5 2 . 2}$ & 52.2 & 100.0 \\
Total & 113 & 100.0 & 100.0 & \\
\hline \hline
\end{tabular}


The data indicate that with respect to functional applications (Figure 4) and experience level (Table 5), beginners tended to be in level $1(55.6 \%)$ and level 2 (44.4\%). Intermediate users tended to spread between level 1 (20\%), level 2 (46\%), and level $3(34 \%)$. Also as shown in Figure 7, beginners tended to use small BIM (intra-departmental data sharing), intermediate tended to use both medium (intra-organizational data sharing) (44\%) and big BIM (interorganizational data sharing) (56\%), while advanced and expert companies all used big BIM.



BIM Level $\square .00$ ThLevel 1 BLevel 3

Figure 6. Level of BIM Use Based on Company Experience.
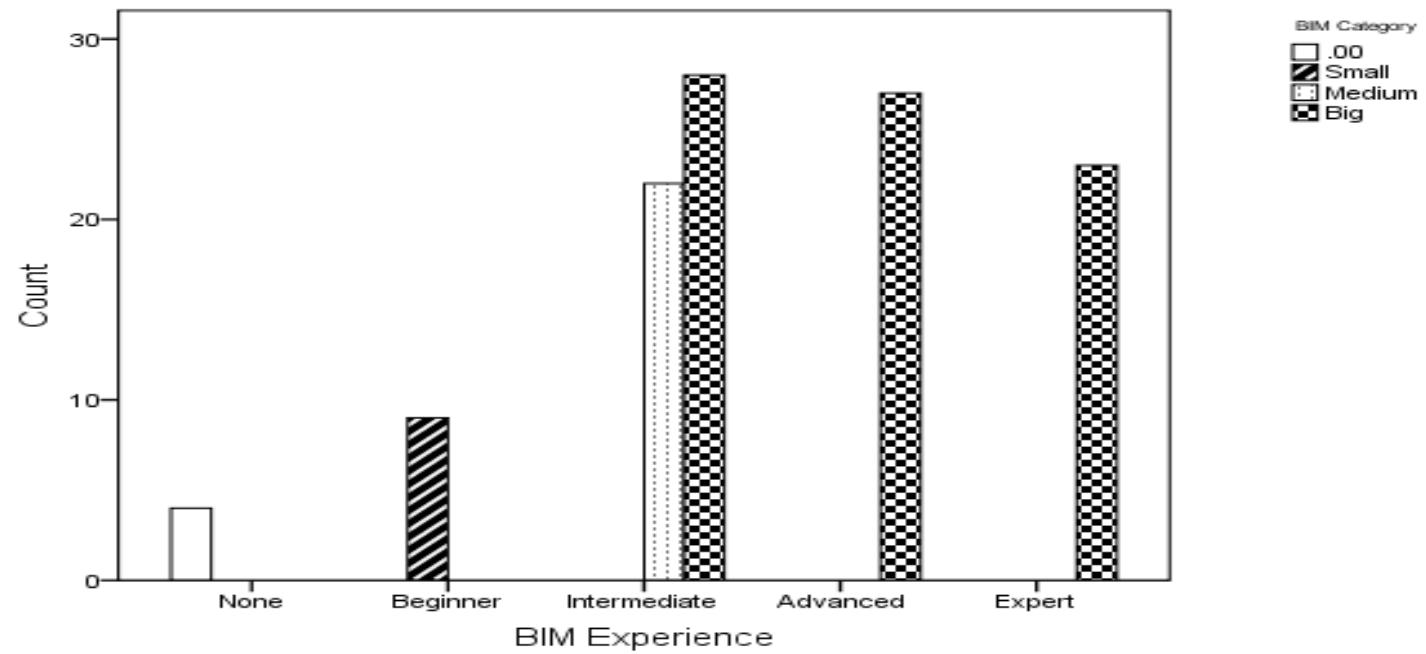

Figure 7. Category of BIM Use Based on Company Experience.

\section{Discussion of findings}

Survey responses revealed that the surveyed construction firms were well established firms within the United States and that majority of them utilize BIM technology. They were mostly large construction firms with over 100 employees and providing a variety of services to their clients including: general contracting, construction management, design build, and design services. Although $96.5 \%$ of the companies indicated that they utilized BIM technology within their construction processes, the extent of use varied substantially. For example, the data indicated that firms that were rated as more experienced tended to utilize BIM technology with higher levels of sophistication. Advanced and expert companies mostly used level 2 and level 3 
functional applications. This means that in addition to the use of BIM technology for document production and visualization using 2D and 3D capabilities, they also use additional functionalities such as: change management of 2D and 3D documents, conflict detection, design validation, and analysis of building performance.

However a closer look at the results also indicated that the majority of firms are primarily using level 1 functionalities. This means that for most of the projects the use of BIM technology is limited to functionalities such as: marketing, drawing production, and visualization purposes as opposed to more advanced capabilities of analyzing building performance. It can therefore be stated that most surveyed firms see business value in level 1 related functionalities and only use more advanced capabilities on selected projects that may have more funding or less schedule constraints. In addition, more experienced firms also tended to be involved in interorganizational sharing of BIM generated data (big BIM). As described by previous studies on the use of BIM technology, greater benefits on the use of BIM technology are achieved when a number of interdisciplinary users commit to the use and sharing of BIM generated data ${ }^{4}$. It can therefore be concluded that as firms become more experienced in the use of BIM technology, they perceive more value and therefore use it for a variety of functional applications beyond document production and change management. This point is confirmed by the fact that more experienced firms used BIM technology in a greater proportion of their projects. However, the data also indicated that in general, a greater proportion of firms use BIM technology on less than $40 \%$ of their projects. This indicates that the use of BIM technology is still evolving and that to some extent traditional processes still prevail. It would be interesting to conduct a longitudinal study to investigate if the proportion of projects using BIM is increasing within these construction firms in the future. The data also indicated that a majority (52.2\%) of the companies generally fell into level 3. With regards to the extent of BIM data sharing, $69 \%$ of the respondents indicated that they share BIM data between different departments within their company and other organizations as well. Only $8 \%$ of the respondents indicated intradepartmental use of BIM data.

\section{Conclusions and recommendations for educators}

This section intends to provide recommendations on how BIM educators can make their BIM curriculum both relevant and current. The study data clearly indicated that a majority of leading construction firms are increasingly utilizing BIM technology to improve their business processes. However, the level of functional applications and extent of data sharing differed significantly based on company BIM level of expertise. Whereas most companies are mostly utilizing level 1 functionalities, the results show that as companies become more experienced with BIM technology, there is a trend towards utilization of level 2 and level 3 applications. Therefore, in order to meet future industry demands, construction engineering faculty interested in aligning their instructional outcomes with current practices need to provide their students with practical skills that include a wide array of BIM concepts related to all three levels of BIM use. It is noted that for construction management students, teaching emphasis should be on the use of different types of BIM models for construction analysis and construction efficiencies as opposed to creation of BIM content. The following topics are recommended: 
Level 1: Introduction to BIM concepts. Topics include use of BIM tools for enhancing communication and visualization in construction, fundamental skills on digital visualization, discussions on available BIM tools including underlying concepts such as object technology, and parametric technology, and hands-on training with some of the leading BIM solutions. These are concepts generally related to small BIM.

Level 2: Use of BIM tools for construction analysis related to geometry such as change management of $2 \mathrm{~d}$ and $3 \mathrm{D}$ data. This includes management of BIM data from a variety of discipline specific models such as architectural, structural, and MEP models and their use for a variety of functions such as design validation, scope clarification, clash/conflict detection etc. Concepts related to BIG BIM such as strategies for effective collaboration with other project stakeholders including issues of interoperability between different BIM applications. Also included here is strategies for extracting useful information from BIM models to enable effective decision making.

Level 3: Use of BIM tools for construction analysis beyond geometry. This includes topics such as estimating, scheduling, energy performance etc. Other BIM-related changes within the industry such as updates on the latest technological advances, and process related topics such as integration of BIM processes into existing workflows, innovative concepts such as integrated project delivery, lean construction, BIM and sustainable construction, legal and insurance issues arising from BIM use, and discussion of future trends.

Concluding thoughts: Due to the cross-disciplinary nature of the construction industry, BIM technology should be integrated throughout the curriculum in industry specific classes. Emphasis should not only be on BIM software but also discussions of the underlying concepts and their effects on processes and Construction Management related workflows. The overall objective should be to focus on coursework that requires the integration of BIM technology as a tool for construction management practices through the integration of information that enhances the knowledge about building systems as a whole. Most importantly, curricular coordination of BIM content and course activities could be used to foster collaboration among disciplines at universities in order provide opportunities for students to become exposed to processes that emulate how BIM is utilized in real world applications. Such coordination and curricular integration among faculty from civil engineering, construction, and architecture could provide valuable professional preparation for students in all AEC related fields.

\section{Bibliography}

1 Kymmell, W. (2008). Building Information Modeling: Planning and managing construction projects with 4D CAD and simulations. Chicago, IL: McGraw Hill.

2 Eastman, C., Lee, G., \& Sacks, R. (2003). Development of a knowledge-rich CAD system for the north American precast concrete industry. Paper presented at the Connecting-Crossroads of Digital Discourse, Acadia22 Conference, Ball State University. Muncie, IN.

3 National Building Information Model Standard project (NBIMS): http://www.facilityinformationcouncil.org/bim/ 
4 Giligan, B., \& Kunz, J. (2007). VDC Use in 2007: Significant value, dramatic growth, and apparent business opportunity (CIFE Technical Rep. No TR171). Palo Alto, CA: Stanford University.

5 Kemlani, L. (2006). The AGC's BIM Initiatives and the Contractor's Guide to BIM. In AECbytes. October 11, 2006. http://www.aecbytes.com/buildingthefuture/2006/AGC_BIM.html

6 AIA Technology in Architectural Practice Call for Entries (2008). http://www.aia.org/SiteObjects/files/TAP_BIM_2008_cfe_final_010808.pdf

7 National Institute of Building Sciences. (2008). http://www.nibs.org/aboutnibs.html

8 The GSA's BIM Pilot Program. (2005). http://www.aia.org/SiteObjects/files/gsa.pdf

9 GSA Mandates on Building Information Modeling. AIA PodNet. 2008. http://www.aia.org/pod_kamhagan

10 Matta, C., Kam, C., Clevenger, C., and Ho, P. (2006). GSA’s National 3D-4D BIM Program. http://www7.nationalacademies.org/ffc/2calvin_kam_gsa.pdf

11 GSA CAD Standards: http://www.gsa.gov/gsa/cm_attachments/GSA_DOCUMENT/CAD_standards_R2NY1-k_0Z5RDZ-i34KpR.pdf

12 Jongeling, R. (2006). A process model for work-flow management in construction (Unpublished doctoral dissertation). Luleå University of Technology, Luleå, Sweden.

13 Foster, L. L. (2008). Legal issues and risks associated with Building Information Modeling technology (Unpublished masters thesis). University of Kansas, Lawrence, KS.

14 Kiviniemi, A., Tarandi, V., Karlshøj, J., Bell, H., \& Karud, O. J. (2008). Review of the development and implementation of IFC compatible BIM (Erabuild Report): The Research Council of Norway. Statsbygg, Norway.

15 Khemlani, L., Timerman, A., Benne, B., \& Kalay, Y. E. (1998). Intelligent representation for computeraided building design. Automation In Construction, 8, 49-71.

16 Eastman, C., Teicholz, P., Sacks, R., \& Liston, K. (2008). BIM handbook: A guide to Building Information Modeling for owners, managers, designers, engineers, and contractors. Hoboken, NJ: John Wiley \& Sons.

17 Jernigan, F. (2007). BIG BIM small bim: The practical approach to Building Information Modeling, integrated practice done the right way! (1st ed.). Salisbury, MD: 4Sites Press.

18 Fox, S., \& Hietanen, J. (2007). Interorganizational use of building information models: Potential for automational, informational and transformational effects. Construction Management and Economics, 25, 289-296.

19 Kymmell, W. (2008). Building Information Modeling: Planning and managing construction projects with 4D CAD and simulations. Chicago, IL: McGraw Hill.

20 Jongeling., R., Emborg, M., Asp, M., \& Olofson, T. (2005). Modelling and simulation of cast in place concrete constructions using N-dimensions (ITstomme Report on SBUF Project No 11333). Department of Civil and Environmental Engineering, Division of Structural Engineering, Luleå University of Technology, Luleå, Sweden.

21 Akbas, R. (2003). Geometry-based modeling and simulation of construction processes (Unpublished doctoral dissertation). Stanford University, Palo Alto, CA.

22 Fischer, M., Haymaker, J., \& Liston, K. (2003). Benefits of 3D and 4D models for facility owners and AEC service providers. In 4D CAD and Visualization in Construction: Developments and Applications: Taylor \& Francis.Routledge USA, 1-32.

23 Hartmann, T., Goodrich, W. E., Fischer, M., \& Eberhard, D. (2007). Fulton street transit center project:3D/4D model application report (CIFE Technical Rep. No TR170). Palo Alto, CA: Stanford University.

24 Engineering News Record (ENR) September 22, 2008. McGraw Hill Companies

\section{Appendix A: Survey Format}

\begin{tabular}{|l|l|}
\hline $\begin{array}{l}\text { Question } \\
\text { No }\end{array}$ & \\
\hline 1 & What services does your company offer to your clients? (select all that apply) \\
\hline
\end{tabular}




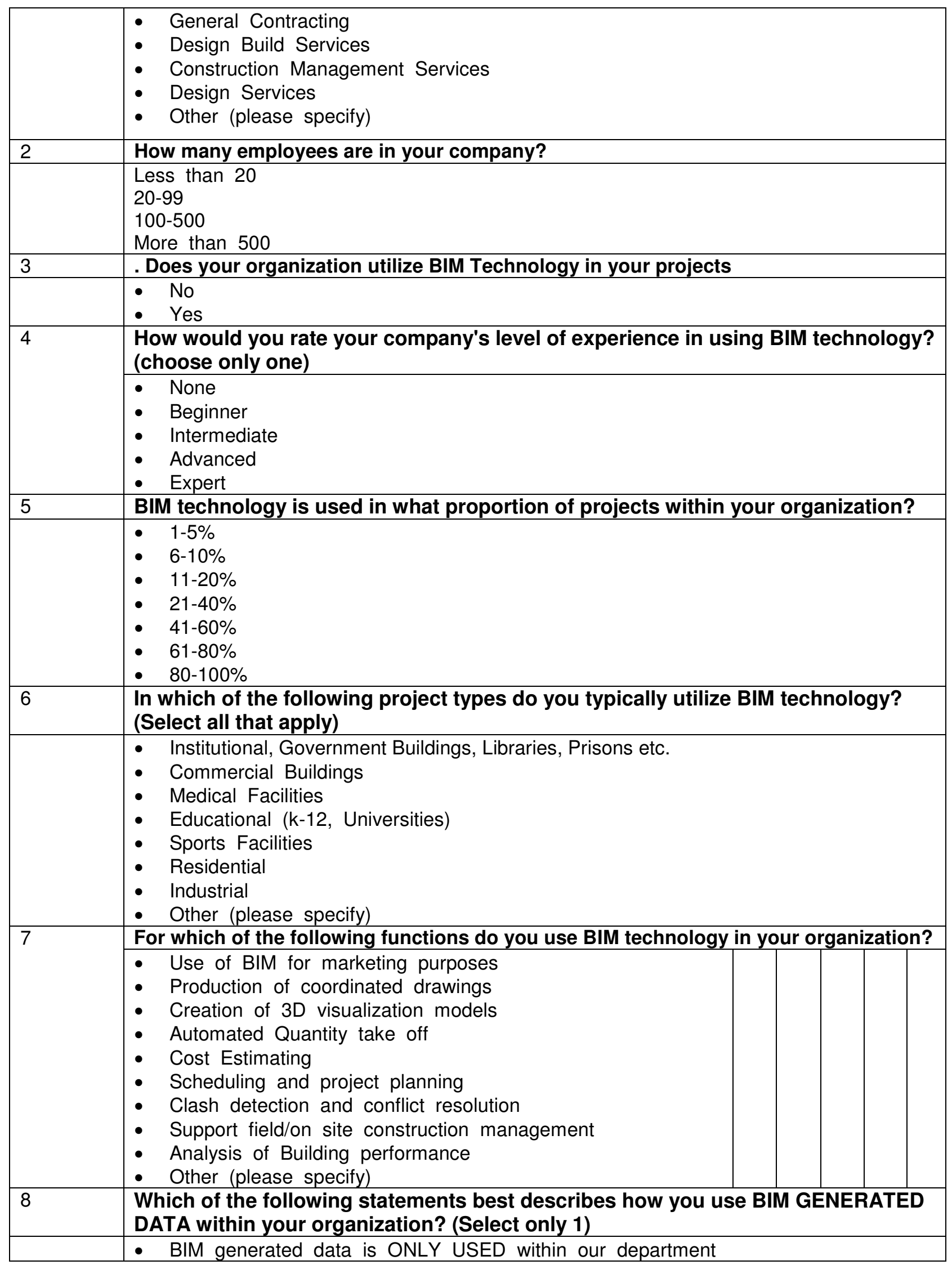




\begin{tabular}{|l|ll|}
\hline & $\begin{array}{l}\text { BIM generated data is SHARED between DIFFERENT DEPARTMENTS WITHIN } \\
\text { our organization } \\
\text { BIM generated data is shared between different departments and OTHER } \\
\text { ORGANIZATIONS as well }\end{array}$ \\
\hline
\end{tabular}

$$
\begin{aligned}
& 0 \\
& \stackrel{0}{0} \\
& \stackrel{D}{0} \\
& \vec{G} \\
& \dot{N} \\
& \vec{\sim} \\
& \vec{\infty}
\end{aligned}
$$

